\title{
Modeling the Performance of Humanitarian Supply Chain Management with the Help of Partial Least Squares (PLS)
}

Ahmad Tavakoli ${ }^{1} \mathbb{D}$, Maryam Aliei $^{2}$

Date of submission: 08 Nov. 2018, Date of acceptance: 02 Feb. 2019

\section{Original Article}

Abstract

INTRODUCTION: Increasing the incidence of natural disasters around the world has led to increased concerns about the social and economic development of developed countries. Natural disasters are inevitable, but they can be taken to reduce their negative impacts on countries. Organizations involved in managing these crises must regulate their supply chain and make the necessary changes to improve the performance of the humanitarian supply chain.

METHODS: Data analysis by partial least squares method (PLS) was performed using smart-pls2 software and a researcher-made questionnaire with 25 questions that examined six structures. In this research, 320 questionnaires have been distributed. In the statistical population of the survey, there are military centers, fire brigades, Omer Crescent population, emergency 115, crisis management and renovation committee in the parliament, governorate, municipalities, supply chain managers, Active practitioners in this field, subject specialists (reference persons and perpetrators in this field), and other members of the organizations involved in rescue and rescue operations in Tehran (randomly selected from the 22 areas). Eventually, 193 people were involved in relief and rescue operations. The reliability of the model has been investigated and verified through three ways of evaluating factor load coefficients, Cronbach's alpha coefficients, composite reliability (CR). The average variance extracted (AVE) values are greater than 0.5 , and CR values are larger than AVEs. That means convergent validity. Also, the mean of the AVE for each structure is greater than 0.50 and this is a sign of convergent validity.

FINDINGS: For the model, GOF is 0.56 ; that means the model has a great fit. The statistics above show that the proposed model is suitable for data collection. In general, the proposed model confirms the relationship between the use of information technology, mutual trust, flexibility, agility, adaptability and performance of the humanitarian supply chain. Fit statistics have four indicators: Goodness of Fitness (GFI) of 0.92, Fitted Goodness Index (AGFI) of 0.9, Root RMSEA error of 0.04 , and $360.88 \times 360$ times. Finally, the ratio of $\mathrm{k}^{2}$ to the degree of freedom for 1.38 is obtained, indicating the good of fitness of the model fit with the data. With the aid of p-values and T-Values 8 hypotheses were confirmed in this modeling.

CONCLUSION: The results show that the agility and flexibility of organizations in the humanitarian supply chain are related to the use of information technology and organizational trust, which in turn affects performance.

Keywords: Human Resource Supply Chain; Performance; Agility; Flexibility; Information Technology

How to cite this article: Tavakoli A, Aliei M. Modeling the Performance of Humanitarian Supply Chain Management with the Help of Partial Least Squares (PLS). Sci J Rescue Relief 2019; 11(1): 1-10.

1-PhD, Department of Management, School of Economics and Administrative Sciences, Ferdowsi University of Mashhad, Mashhad, Iran 2- PhD, Department of Management, Payame Noor University, Tehran, Iran

Correspondence to: Ahmad Tavakkoli, Email: tavakoli-a@um.ac.ir 


\section{Introduction}

$\mathrm{I}$ $\mathrm{n}$ recent years, physicians and academics have paid a great attention to the humanitarian aid supply chains aiming to improve performance in rescue operations. With the increasing rate of natural disasters such as earthquakes, floods, storms and hurricanes, fires, plane crashes, and shipwrecks, there is a growing concern among the countries. The casualties and ruins caused by these disasters with a natural or human origin may take place at any point in the world, and may be along with disastrous outcomes (1-3). The impact of the natural disasters on the human life is evident and these disasters always impose huge damages on the economy of the countries.

Assuming that the demands are constantly changing and there are differences in the magnitude and severity of the disaster as well as the disaster area, prior resources and planning may not be effective for all events that may take place. In today's world, events occurring in one country may influence other countries as well. For example, global financial crises affect every country in the world in practice. To overcome these circumstances, all beneficiaries must act in harmony. However, coordination cannot be achieved in the short term, as factors such as trust among the beneficiaries influence this coordination. Rogers et al., for instance, stated that if organizations trust each other, they would be more likely to work together (4). The coordination among the active individuals supports the proper crisis management. For example, the supplemental plans can maximize the use of the resources that are limited in terms of time, capital, and human resources.

The ability of the active individuals to respond to the varying demands in the humanitarian supply chain (HSC) is of a paramount importance. Regarding the commercial supply chain (CSC), flexibility refers to the methods in which the smooth flow of products can be guaranteed (5). In addition, the flexibility of the HSC indicates the ability of the active individuals to respond to the unexpected requirements and demands of the individuals affected by the event, which includes the speed of delivery of food, water, drugs, clothing, blankets, etc. to the affected individuals. Agility represents the power of interaction between an organization and the market for an organization (6). In this study, agility has been defined as the capability of an organization to quickly adapt to the event-induced changes in different situations. Agility is a feature of the organizations that can perceive the short-term changes in the chaotic situation caused by the events such as supply and demand fluctuations and the rapid and flexible response required to cope with these circumstances.

Utilization of the information technology (IT) is an emerging priority for organizations in managing their CSC. For instance, the IT capabilities are required in managing the knowledge, changes, assets, and the CSC. In this way, the application of IT in the HSC reduces the negative impacts of the natural disasters in the society, which is a step towards improving the economic and development conditions of the country in the long run (7-10). To understand the advantages of IT, it must be combined with other factors producing valuable sustainable resources $(9,10)$. These factors are flexibility, agility, mutual trust, adaptability, and performance (11-13).

Mutual trust is an important property for a business which is somehow involved in the information acquisition and sharing methods. In this study, the trust among organizations involved in the disaster rescue operations process has been investigated. Regarding the relation among the organizations, the mutual trust is defined as the expectations of a company with respect to the responsibilities of the other company and the behavioral or ethical values assuming the possibility of an opportunistic behavior $(14,15)$. Besides, adaptability has been described as the capability of changing in a given state. In this study, the adaptability has been defined with a wider context as the ability to change or adapt quickly in a timely manner in the current environment. This could include building new warehouses, changing the selection of suppliers or other service providers, or implementing the custom commercial resources which are planned in a flexible manner by adjusting the supply chain network. The application of IT enhances the mutual trust and quality of the current information among the organizations in the CSC, leading to the increased competitive performance of each organization. Moreover, agility, flexibility, IT, and particularly the CSC are all related to each other.

Furthermore, our knowledge of the relationships among the application of IT, flexibility, agility, adaptability, and performance is often limited to the concept of the CSC (16). 
Examining these similar relationships in the HSC field leads to the interesting results. As the number of studies conducted on the crisis and emergencies management has increased (17-21), relatively few studies have addressed the HSC issue experimentally and quantitatively $(22,23)$. Therefore, in this study, it has been attempted to address this important research requirement. The objective in this study was to better understand the relationships among IT, mutual trust, agility, flexibility, adaptability, and performance in the HSC field.

It has been declared the communication and coordination to be necessary to increase the transparency of the existing systems. This helps to exploit the IT systems in the incident management. Therefore, the rescue team members need to cooperate closely on natural disasters and adjust and modify or rebuild their resource chains with increasing agility, flexibility, and adaptability to the circumstances. In the rescue operations, the active individuals are from among various beneficiaries and organizations that are directly or indirectly involved in the rescue operations (1,24). To decrease the incident uncertainty risks, the organizations must continuously identify and evaluate their operating environments in order to progress. Factors that enhance the performance of the organizations during the rescue operations must be constantly examined (25). This study has presented guidance to smaller organizations to understand the important factors in upgrading the performance of the human resource chain. In this study, the relationship among the use of IT, mutual trust, flexibility, agility, and adaptability on the performance of the HSC has been presented for the first time.

These organizations must have a concordant function after the event to reduce the negative impacts of the event on the society. Collaboration between groups leads to the formation of a supply chain (SC). In a study carried out by Hall et al. (26), the SC definition proposed by Christopher and Towill (27) is quoted as saying that $\mathrm{SC}$ is a network of organizations that are involved in different processes and activities that produce value through higher and lower communications, in the form of products and services delivered to the end consumer.

$\mathrm{SC}$ and HSC is a network of members that support the flow of goods, information, and capital from the source to the end customer (28). The only difference is that the customers in the HSC include the individuals affected by the incident and the benevolent individuals who play a supporting role in improving the performance of the HSC (29-31).

The following study deals with the theoretical framework and assumptions presented in the development of the hypothesis and the theoretical framework. The study method has been outlined in the analysis and design section. In the results and data analysis section, the results of the data analysis can be observed. In the discussion section, the study findings are described. In addition, the conclusion section addresses the limitations and capacities for future studies.

\section{Methods}

This applied study was performed using the descriptive-survey method. The partial least squares (PLS) method is a path modeling method based on the univariate and multivariate regression that estimates the path coefficients and variances for the model (32). Therefore, it may have several dependent variables. To establish a relationship between the dependent and independent variables, the PLS method creates new explanatory (independent) variables. In contrast to the covariance-based structural equation modeling (SEM), the PLS method focuses on the highest variance of the dependent variables explained by the independent variables instead of reproducing the experimental covariance matrix. As with any SEM, the PLS method is comprised of a structural section indicating the relationship between the latent variables and a measurement component that reflects the relationship between the latent variables and their markers. The PLS method is highly useful for analyzing the structural models with several variables (33-37).

Flexibility is the key characteristic of an agile organization (38-40) and the application of IT is beneficial for the organizations to enhance their agility, flexibility, and performance (41-43). A conceptual model has been depicted in figure 1 to examine the relationship between the IT application and mutual trust, flexibility, agility, adaptability, and performance. In this study, the application of IT and mutual trust was not considered from the point of view of an organization, but rather from a HSC perspective. 


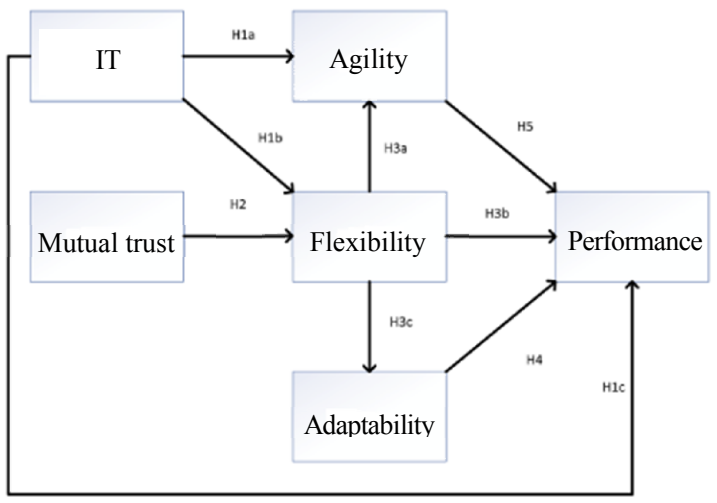

Figure 1. Conceptual model of the study

The hypotheses investigated in the current study were as follows:

Hypothesis 1a: The application of IT has a positive effect on the agility of the organizations involved in HSC.

Hypothesis 1b: The application of IT has a positive effect on the flexibility of the organizations involved in HSC.

Hypothesis 1c: The application of IT has a positive effect on the performance of the organizations involved in HSC.

Hypothesis 2: Mutual trust has a positive effect on the flexibility of the organizations involved in HSC.
Hypothesis 3a: Flexibility has a positive effect on the agility of the organizations involved in HSC.

Hypothesis 3b: Flexibility has a positive effect on the adaptability of the organizations involved in HSC.

Hypothesis 3c: Flexibility has a positive effect on the performance of HSC.

Hypothesis 4: Agility has a positive effect on the performance of HSC.

Hypothesis 5: Adaptability has a positive effect on the performance of HSC.

For this study, a survey method was employed to experimentally examine the above-mentioned relationships. According to several researchers, such as Gall et al. (44), Schneider et al. (45) and Smith and Dainty (46), the survey method is a useful tool to estimate the unobservable phenomena such as the employees' perceptions of the organization or the relationship between different processes and their proportion. In addition in this study, the guidelines provided in the studies by Flynn et al. (47) and Hair et al. (48) were followed. The data were collected and utilized to test the above-mentioned hypotheses.

The measurement tool in this study was a researcher-made questionnaire, with the items examined in the study and the questions outlined by the researcher listed in Table 1 .

Table 1. Items and dimensions of the researcher-made questionnaire in accordance with the previous studies $(1,12,13,25,49-51)$

$\begin{array}{lcc}\text { Variable } & \text { IT1 } & \text { Tuestionnaire item } \\ \text { IT } & \text { The organization uses the transfer of IT to the international organizations. } \\ \text { The organization uses the transfer of IT to the domestic organizations. } \\ \text { The organization uses IT to create and store information for the future. } \\ \text { The organization uses IT to manage the rescue materials. }\end{array}$

IT: Information technology; SC: Supply chain 
The dimensions investigated were outlined by several researchers $(1,12,13,25,49-51)$.

In the present study, a five-point Likert scale (1-5) was employed with the items obtained from the previously used multiple-item scales. The criteria for applying IT reflected its use in various SC activities such as inventory management, procurement, regulation, distribution, and coordination of the organizations involved in the rescue operations, which included the perceived value of the managers active in the organizations. The mutual trust criteria indicated the trust in the shared information for their mutual advantages to enhance the efficiency of the rescue operations.

The flexibility criteria enable an organization to deliver or change products or services in the shortest time with the ability to quickly change the transfer mode. The HSC adaptability criteria are indicative of the ability of the active individuals to quickly adapt to the limitations in the event coping phase, including the management of the cultural differences among the organizations regarding the constraints of a number of partners. The agility criteria reflect the levels of information sharing, cooperative work, and development planning to improve the customer service to upgrade the rescue operations efficiency. Finally, the performance criteria show the way of coping with an incident, which include the criteria for the speed of preparation of medical and auxiliary facilities.

The PLS method was employed to analyze the hypotheses proposed in this study. This technic requires less sample size compared to other modeling technics to respond to the hypotheses in the model. According to Chin and Newsted, an acceptable sample size for a multiple regression study at a test power level of 0.8 , significance level of 0.05 , and effect size of 0.15 is 108 (52). As a general rule, the sample size in the PLS method should be 10 times the number of the model variables (53); since there were 6 variables in this study, based on this method, the sample size had to be greater than 60 .

Additionally, Barclay et al. suggested that the sample size for the PLS method should be at least ten times the maximum number of construct paths directed to a particular construct in the internal path model (54). In this model, the variables of flexibility, agility, and performance with 9 relationships had the highest level of relationship, i.e. the acceptable sample size for the current model was 90.

To ensure the validity of the questionnaire, the specialists (professors) in the SC management field reviewed it. These professors had an experience of over 5 years and have published several research studies and case studies in the internationally accredited journals. After reviewing and submitting comments by the professors, some items were removed and redesigned for more clarity. Moreover, the questionnaire was pilot tested with 22 respondents.

For this purpose, to obtain 90 samples, 320 questionnaires were distributed in the target statistical population including military centers, fire departments, Red Crescent Society, Emergency 115, parliament committee on the crisis management and renovation, provincial government, governorate, municipalities, SC managers, physicians active in this field, subject specialists, (reference individuals and influential people in this field), and other members of the organizations involved in rescue operations in Tehran City, Iran, who were selected using the random clustering method from 22 districts. These organizations were selected based on their presence in the rescue operations as published in the media and newspapers. However, to ensure their participation in the rescue operations, the introduction section was included in the questionnaire. In case of the lack of presence of the individuals at the operation, their responses were eliminated from the study to retain the generality of the results. Then, 209 questionnaires were completed and received from those who had participated at least in one rescue mission. Of these questionnaires, 16 were excluded due to the provision of the incomplete information. Finally, $193(60 \%)$ questionnaires, which is an acceptable rate for such surveys (55), were considered in this study. At last, the participants in the study included 193 individuals involved in the rescue operations.

\section{Findings}

Table 2 presents the demographic characteristics of the subjects, including age, experience level, and gender.

$40,22,20,10$, and 8 percent of the responses was associated with the organizations with a personnel number of less than 50, 101-200, 50-100, 200-300, and more than 300, respectively.

As illustrated in the primary conceptual model of the study (Figure 1), the resulting variable is a 
reflective variable. Moreover, for complex models in which there is little theoretical information and the analysis can be performed even with 30 questionnaires, the PLS is a very useful method.

Table 2. Demographic characteristics of the subjects

\begin{tabular}{|l|c|c|c|}
\hline Descriptive characteristics of samples & n & \% \\
\hline Age (year) & Less than 30 & 84 & 44 \\
& $31-40$ & 68 & 35 \\
\hline \multirow{2}{*}{ Experience (year) } & 41 and higher & 41 & 21 \\
& Less than 10 & 102 & 53 \\
& $10-20$ & 48 & 25 \\
Gender & More than 20 & 43 & 22 \\
& Female & 155 & 80 \\
\hline
\end{tabular}

A measurement model is part of a general model that includes a variable with items about that variable. The three criteria of reliability, convergent validity $(\mathrm{CV})$, and discriminant validity are exploited to examine the fitting of the models. The reliability itself is evaluated by three ways: factor load coefficients, Cronbach's alpha coefficients, and composite reliability (CR). Generally, if the Cronbach's alpha and $\mathrm{CR}$ values are higher than 0.8 and the average variance extracted (AVE) value is greater than 0.5 , it can be declared that the measurement tool (questionnaire) has been able to well measure the desired latent variables.
In this study, the Cronbach's alpha coefficient for all constructs was higher than 0.70 , as represented in Table 3 indicating a high reliability. The standardized factor loading for each item employed in this study ranged from 0.652 to 0.928 . The items used in the study had content validity as the choice of the measurement items was based on a comprehensive review of the literature as well as the evaluations by the experts. Furthermore, for $\mathrm{CV}$, as shown in the table, all the $\mathrm{CR}$ values were greater than 0.7 , and the AVE values were greater than 0.5 , hence the $C R$ values are greater than the AVE values. That is, $C V$ was confirmed.

In addition, AVE was used to examine $\mathrm{CV}$ for each construct, which was greater than 0.50, indicating that $\mathrm{CV}$ was confirmed. In addition, the Fornell and Larker criterion was employed to investigate the discriminant validity. This method implied that a construct in the model had a higher interaction with its indices in comparison to the other constructs. The discriminant validity was acceptable when the AVE value for each construct was greater than the shared variance between that construct and other constructs in the model. This issue was examined by a matrix the places of which contained the values of the correlation coefficients between the constructs and the square root of the AVE values for each construct.

Table 3. Analysis of reliability, convergent validity (CV), and discriminant validity of the model variables

\begin{tabular}{|c|c|c|c|c|c|c|c|c|}
\hline \multicolumn{2}{|l|}{ Variable } & $\begin{array}{l}\text { Standardized } \\
\text { factor load }\end{array}$ & $\mathbf{P}$ & CR & AVE & $\begin{array}{l}\text { Cronbach's } \\
\text { alpha }\end{array}$ & MSV & ASV \\
\hline \multirow{4}{*}{ IT } & IT1 & 0.885 & 39.106 & \multirow{4}{*}{0.923} & \multirow{4}{*}{0.750} & \multirow{4}{*}{0.889} & \multirow{4}{*}{0.04} & \multirow{4}{*}{0.02} \\
\hline & IT2 & 0.859 & 31.222 & & & & & \\
\hline & IT3 & 0.883 & 42.870 & & & & & \\
\hline & IT4 & 0.837 & 18.466 & & & & & \\
\hline \multirow{3}{*}{ Mutual trust } & MT1 & 0.800 & 16.017 & \multirow{3}{*}{0.906} & \multirow{3}{*}{0.763} & \multirow{3}{*}{0.844} & \multirow{3}{*}{0.05} & \multirow{3}{*}{0.02} \\
\hline & MT2 & 0.903 & 39.665 & & & & & \\
\hline & MT3 & 0.914 & 53.243 & & & & & \\
\hline \multirow{4}{*}{ Flexibility } & HSF1 & 0.868 & 41.884 & \multirow{4}{*}{0.952} & \multirow{4}{*}{0.832} & \multirow{4}{*}{0.932} & \multirow{4}{*}{0.04} & \multirow{4}{*}{0.03} \\
\hline & HSF2 & 0.928 & 65.324 & & & & & \\
\hline & HSF3 & 0.922 & 53.983 & & & & & \\
\hline & HSF4 & 0.928 & 63.013 & & & & & \\
\hline \multirow{3}{*}{ Adaptability } & HSCA1 & 0.806 & 16.897 & \multirow{3}{*}{0.866} & \multirow{3}{*}{0.684} & \multirow{3}{*}{0.768} & \multirow{3}{*}{0.05} & \multirow{3}{*}{0.02} \\
\hline & HSCA2 & 0.885 & 30.805 & & & & & \\
\hline & HSCA3 & 0.786 & 14.984 & & & & & \\
\hline \multirow{6}{*}{ Agility } & HSCAG1 & 0.817 & 27.763 & \multirow{6}{*}{0.945} & \multirow{6}{*}{0.743} & \multirow{6}{*}{0.930} & \multirow{6}{*}{0.06} & \multirow{6}{*}{0.03} \\
\hline & HSCAG2 & 0.906 & 49.095 & & & & & \\
\hline & HSCAG3 & 0.871 & 41.464 & & & & & \\
\hline & HSCAG4 & 0.893 & 59.644 & & & & & \\
\hline & HSCAG5 & 0.855 & 32.300 & & & & & \\
\hline & HSCAG6 & 0.825 & 28.48 & & & & & \\
\hline
\end{tabular}

IT: Information technology; CR: Composite reliability; AVE: Average variance extracted; MSV: Maximum shared variance; ASV: Average shared variance 
Table 4. Discriminant validity assessment matrix by Fornell and Larker method

\begin{tabular}{|c|c|c|c|c|c|c|}
\hline Variable & Adaptability & Agility & Flexibility & IT & Mutual trust & Performance \\
\hline Adaptability & 0.827 & & & & & \\
\hline Agility & 0.331 & 0.862 & & & & \\
\hline Flexibility & 0.246 & 0.477 & 0.912 & & & \\
\hline IT & 0.32 & 0.577 & 0.373 & 0.866 & & \\
\hline Mutual trust & 0.082 & 0.353 & 0.462 & 0.355 & 0.874 & \\
\hline Performance & 0.296 & 0.652 & 0.568 & 0.518 & 0.595 & 0.752 \\
\hline
\end{tabular}

IT: Information technology

That is, the square root of AVE for each construct was greater than the correlation coefficient of the other constructs, as illustrated in Table 4 (52,56). Moreover, since for each component, MSV $<$ AVE and ASV $<$ AVE, the discriminant validity of the components was confirmed. Furthermore, the results indicated that the subscales were not so highly correlated that they could form a construct and hence the components were not repetitive.

The goodness of fit (GOF) value for the model was 0.56 , indicating a good fit for the model (57). The above statistic revealed that the proposed model was suitable for data collection. In general, it confirmed the relationships between the use of IT and mutual trust, flexibility, agility, adaptability, and the performance of HSC.

Different methods are used to test the model and its paths. One of the methods available is the GOF index and among the fit statistics, four indices of goodness of fit index (GFI), adjusted goodness of fit index (AGFI), root mean square error of approximation (RMSEA), and chi-square have been reported as 0.92, 0.90, 0.04, and 360.88, respectively. Finally, the chi-square to degree of freedom ratio was obtained as 1.38 , indicating good fit of the model with the data. Table 5 demonstrates the model goodness of fit indices.

Table 5. Model goodness of fit indices

\begin{tabular}{|c|c|c|c|c|c|}
\hline AGFI & GF] & RMSEA & $\mathbf{P}$ & $\begin{array}{l}\text { Degree of } \\
\text { freedom }\end{array}$ & $\begin{array}{c}\text { Chi- } \\
\text { square }\end{array}$ \\
\hline 0.90 & 0.92 & 0.03 & 0.001 & 260 & 360.88 \\
\hline
\end{tabular}

Table 6 shows the results of investigation of the study hypotheses. Accordingly, the application of IT has positively influenced the agility, flexibility, and performance within the HSC framework, as the results indicated that the standardized path coefficients for hypotheses H1a, H1b, and H1c were within the acceptable range and the T-value was greater than the critical value of 1.96, confirming the hypotheses.

Similarly, the mutual trust has positively affected the flexibility in HSC, thus $\mathrm{H} 2$ was accepted as well because the T-Value was greater than the critical value and the value of the standardized path coefficient for $\mathrm{H} 2$ was 0.377 , which was within the acceptable range, hence confirming the $\mathrm{H} 2$ hypothesis.

Moreover, the flexibility positively affected the organizational agility, adaptability, and performance as based on the results, the standardized path coefficients for $\mathrm{H} 3 \mathrm{a}, \mathrm{H} 3 \mathrm{~b}$, and $\mathrm{H} 3 \mathrm{c}$ were within the acceptable range and the Tvalues were higher that the critical value, thus the hypotheses were confirmed.

Furthermore, the organizational adaptability was not positively correlated with the HSC performance, and hypothesis $\mathrm{H} 4$ was rejected. Because the T-Value was 0.58 and lower that the critical value of 1.96 , besides, the standardized path coefficient for $\mathrm{H} 4$ was 0.036 , which was not within the acceptable range and did not confirm the hypothesis.

Finally, the agility of an organization positively influenced the performance of the humanitarian operations, and hence hypothesis H5 was confirmed, as the T-Value was greater than the critical value and the standardized path coefficient value for $\mathrm{H} 5$ was 0.493 , which was within the acceptable range.

\section{Conclusion}

The current study was the first of its type carried out taking into account the relationship between the use of IT, mutual trust between organizations and individuals, flexibility, agility, and adaptability with the HSC performance. This study suggested a unique solution to bridge the research gap in the HSC literature; meanwhile, more experimental studies are required to be accomplished in the HSC management field.

The results indicated that the agility and flexibility in a HSC were along with the IT 
Table 6. Summary of the results of assessment of the study hypotheses

\begin{tabular}{lccccc} 
Hypothesis & $\begin{array}{c}\text { Standardized } \\
\text { path coefficient }\end{array}$ & Statistic t & P & $\begin{array}{c}\text { Result of } \\
\text { hypothesis }\end{array}$ \\
H1a & Effect of IT on agility & 0.464 & 9.333 & $<0.001$ & Confirmed \\
H1b & Effect of IT on flexibility & 0.419 & 3.858 & $<0.001$ & Confirmed \\
H1c & Effect of IT on performance & 0.551 & 2.207 & $<0.050$ & Confirmed \\
H2 & Effect of mutual trust on flexibility & 0.377 & 6.233 & $<0.001$ & Confirmed \\
H3a & Effect of flexibility on agility & 0.304 & 4.982 & $<0.001$ & Confirmed \\
H3b & Effect of flexibility on adaptability & 0.546 & 3.661 & $<0.001$ & Confirmed \\
H3c & Effect of flexibility on performance & 0.509 & 4.021 & $<0.001$ & Confirmed \\
H4 & Effect of adaptability on performance & 0.036 & 0.58 & $<0.050$ & Rejected \\
H5 & Effect of agility on performance & 0.493 & 4.529 & $<0.001$ & Confirmed \\
\hline
\end{tabular}

application, which in turn is correlated with performance. The results also showed that the application of IT was positively correlated with the agility, flexibility, and performance of the SC. Additionally, the mutual trust was significantly related to the HSC flexibility and the HSC flexibility had a positive effect on the adaptability, agility, and performance of the HSC. Ultimately, adaptability did not significantly affect the HSC performance. This study is expected to be useful for smaller organizations with guidelines to perceive the critical factors for improving the HSC performance.

The findings of the present study are in line with the results of previous studies (58). The results suggested that the IT application in HSC positively affected the agility, flexibility, and performance of the organizations involved in rescue operations to improve the conditions in the society. The findings of this study are also in agreement with those of other studies performed in the area of CSC. Youn et al. investigated the direct impact of mutual trust on flexibility (13). Similarly, the findings of this study revealed that there was a positive relationship between mutual trust and the SC flexibility, suggesting that mutual trust among the organizations involved in SC can be used as a "silver bullet" in many areas of the SC management (59).

Furthermore, the results of this study were indicative of the positive effects of the HSC flexibility on agility, adaptability, and performance of HSC. This is in line with the study by Dubey et al. (60). Flexibility can be achieved from the longterm planning, however adaptability stems from the short-term planning. In order to improve the adaptability of the organizations in the HSC network, the focus should be on the local culture, developing an attitude of sharing, and trust among organizations as well as responding to the environmental requirements.

This finding also confirms the results of the study by Maiers et al. (61), reporting that sharing information among members of the HSC is essential to improve its performance. Distribution of the proper information at the right place and time among the right individuals is one of the most important cases that should be regarded in knowledge sharing (61-64).

\section{Acknowledgments}

None

\section{Conflict of Interests}

Authors have no conflict of interests.

\section{References}

1. Kovacs G, Spens K. Humanitarian logistics in disaster relief operations. Int J Phys Distrib Logist Manag 2007; 37(2): 99-114.

2. Tomasini RM, Van Wassenhove LN. From preparedness to partnerships: Case study research on humanitarian logistics. Int Trans Oper Res 2009; 16(5): 549-59.

3. Yamada S, Gunatilake RP, Roytman TM, Gunatilake S, Fernando T, Fernando L. The Sri Lanka Tsunami Experience. Disaster Manag Response 2006; 4(2): 38-48.

4. Rogers P, Burnside-Lawry B, Dragisic J, Mills C. Collaboration and communication: Building a research agenda and way of working towards community disaster resilience. Disaster Prev Manag 2016; 25(1): 75-90.

5. Lummus RR, Vokurka RJ, Duclos LK. Delphi study on supply chain flexibility. Int $\mathrm{J}$ Prod Res 2005; 43(13): 2687-708.

6. Katayama H, Bennett D. Agility, adaptability and leanness: A comparison of concepts and a study of practice. Int J Prod Econ 1999; 60-61: 43-51. 
7. Andrade AD, Urquhart C. Unveiling the modernity bias: A critical examination of the politics of ICT4D. Information Technology for Development 2012; 18(4): 281-92.

8. $\mathrm{Hu} \mathrm{Q}$, Kapucu $\mathrm{N}$. Information communication technology utilization for effective emergency management networks. Pub Manag Rev 2016; 18(3): 323-48.

9. Clemons EK, Row MC. Sustaining IT Advantage: The role of structural differences. MIS Quarterly 1991; 15(3): 275-92.

10. Powell TC, Dent-Micallef A. Information technology as competitive advantage: The role of human, business, and technology resources. Strat Mgmt J 1997; 18(5): 375-405.

11. Kivunike FN, Ekenberg L, Danielson M, Tusubira FF. Perceptions of the role of ICT on quality of life in rural communities in Uganda. Info Technol Develop 2011; 17(1): 61-80.

12. Ye F, Wang Z. Effects of information technology alignment and information sharing on supply chain operational performance. Comput Ind Eng 2013; 65(3): 370-7.

13. Youn SH, Yang MG, Kim JH, Hong P. Supply chain information capabilities and performance outcomes: An empirical study of Korean steel suppliers. Int J Inf Manage 2014; 34(3): 369-80.

14. Zaheer A, McEvily B, Perrone V. Does Trust Matter? Exploring the effects of interorganizational and interpersonal trust on performance. Organization Science 1998; 9(2): 123-251.

15. Bordoloi SK, Cooper WW, Matsuo H. Flexibility, adaptability, and efficiency in manufacturing systems. Prod Oper Manag 1999; 8(2): 133-50.

16. Swafford PM, Ghosh S, Murthy N. The antecedents of supply chain agility of a firm: Scale development and model testing. J Oper Manag 2006; 24(2): 170-88.

17. Adeagbo A, Daramola A, Carim-Sanni A, Akujobi C, Ukpong C. Effects of natural disasters on social and economic well being: A study in Nigeria. Int $\mathbf{J}$ Disaster Risk Reduct 2016; 17: 1-12.

18. Albright EA, Crow DA. Learning in the aftermath of extreme floods: Community damage and stakeholder perceptions of future risk. Risk Hazards \& Crisis in Public Policy 2015; 6(3): 308-28.

19. Harte $W$, Sowman $M$, Hastings $P$, Childs I. Barriers to risk reduction: Dontse Yakhe, South Africa". Disaster Prev Manag 2015; 24(5): 651-69.

20. Kuipers SL, Boin RA. Building Joint crisis management capacity? Comparing civil security systems in 22 European countries. Risk, Hazards \& Crisis in Public Policy 2015; 6(1): 21.

21. Robinson S, Murphy H, Bies A. Structured to partner: School district collaboration with nonprofit organizations in disaster response. Risk, Hazards \& Crisis in Public Policy 2014; 5(1): 77-95.

22. Kunz N, Reiner G. A meta-analysis of humanitarian logistics research. Journal of Humanitarian Logistics and Supply Chain Management, 2012; 2(2): 116-47.

23. Kovacs G, Spens K. Humanitarian logistics and supply chain management: The start of a new journal. Journal of Humanitarian Logistics and Supply Chain Management 2011; 1(1): 5-14.

24. Valero J, Jung K, Andrew S. Does transformational leadership build resilient public and nonprofit organizations? Disaster Prev Manag 2015; 24(1): 4-20.

25. Lowry PB, Gaskin JE. Partial least squares (PLS) structural equation modeling (SEM) for building and testing behavioral causal theory: When to choose it and how to use it. IEEE Trans Prof Commun 2014; 57(2): 123-46.

26. Hall DJ, Skipper JB, Hanna JB. The mediating effect of comprehensive contingency planning on supply chain organisational flexibility. International Journal of Logistics Research and Applications 2010; 13(4): 291-312.

27. Christopher M, Towill D. An integrated model for the design of agile supply chains. International Journal of Physical Distribution \& Logistics Management 2001; 31(4): 235-46.

28. Overstreet R, Hall D, Hanna J, Kelly Rainer R. Research in humanitarian logistics. Journal of Humanitarian Logistics and Supply Chain Management 2011; 1(2): 114-31.

29. Chan TC, Killeen J, Griswold W, Lenert L. Information technology and emergency medical care during disasters. Acad Emerg Med 2004; 11(11): 1229-36.

30. Jefferson $\mathrm{T}$. Evaluating the role of information technology in crisis and emergency management. VINE 2006; 36(3): 261-4.

31. Telleen S, Martin E. Improving information access for public health professionals. J Med Syst 2002; 26(6): 529-43.

32. Hall D, Skipper J, Hazen B, Hanna J. Interorganizational IT use, cooperative attitude, and inter-organizational collaboration as antecedents to contingency planning effectiveness. Int $\mathrm{J}$ Logist Manag 2012; 23(1): 50-76.

33. Narasimhan R, Swink M, Kim SW. Disentangling leanness and agility: An empirical investigation. J Oper Manag 2006; 24(5): 440-57.

34. National Research Council. Reducing disaster losses through better information. Washington, DC: National Academies Press; 1999.

35. Lee HW, Zbinden M. Marrying logistics and technology for effective relief. Forced Migr Rev 2003; 18: 34-5.

36. Clay Whybark D. Issues in managing disaster relief inventories. Int J Prod Econ 2007; 108(1): 228-35.

37. Boyson S, Corsi T, Verbraeck A. The e-supply chain portal: A core business model. Transp Res E: 
Log Trans Rev 2003; 39(2): 175-92.

38. Pettit S, Beresford A. Critical success factors in the context of humanitarian aid supply chains. Int $\mathbf{J}$ Phys Distrib Logist Manag 2009; 39(6): 450-68.

39. Whang $\mathrm{S}$. Information sharing in a supply chain. Int J Technol Manag 2000; 20(3/4): 373-87.

40. Thomas A. Humanitarian logistics: Enabling disaster response. San Francisco, CA: Fritz Institute; 2003.

41. Blecken A. Humanitarian logistics: Modelling supply chain processes of humanitarian organisations. Bern, Switzerland: Haupt Verlag AG; 2010.

42. Whitten GD, Green KW, Zelbst PJ. Triple-A supply chain performance. Int J Oper Prod Manag 2012; 32(1): 28-48.

43. Stevenson M, Spring M. Flexibility from a supply chain perspective: Definition and review. Int J Oper Prod Manag 2007; 27(7): 685-713.

44. Gall MD, Borg WR, Gall JP. Educational research: An introduction. London, UK: Longman; 1996.

45. Schneider B, Ashworth SD, Higgs AC, Carr L. Design, validity, and use of strategically focused employee attitude surveys. Pers Psychol 1996; 49(3): 695-405.

46. Smith NC, Dainty P. The management research handbook. London, UK: Routledge; 1991.

47. Flynn BB, Sakakibara S, Schroeder RG, Bates KA, Flynn EJ. Empirical research methods in operations management. J Oper Manag 1990; 9(2): 250-84.

48. Hair JF, Bill B, Barry B, Anderson RE, Tatham RT. Multivariate data analysis. Upper Saddle River, NJ: Prentice Hall; 2009.

49. Moon KK-L, Yi CY, Ngai EWT. An instrument for measuring supply chain flexibility for the textile and clothing companies. Eur J Oper Res 2012; 222(2): 191-203.

50. Roh S, Beresford AK, Pettit SJ. Humanitarian aid logistics: Response depot networks. Proceedings of the $20^{\text {th }}$ NOFOMA Conference; 2008 June 5-6; Helsinki, Finland.

51. Tatham P, Spens K. Towards a humanitarian logistics knowledge management system. Disaster Prev Manag 2011; 20(1): 6-26.

52. Chin WW, Newsted PR. Structural equation modeling analysis with small samples using partial least squares. In Hoyle RH, Editor. Statistical strategies for small sample research. Thousand
Oaks: CA: Sage Publications. p. 307-41.

53. Gefen D, Straub D, Boudreau MC. Structural equation modeling and regression: Guidelines for research practice. Communications of the Association for Information Systems: 2000; 4(1): 1-77.

54. Barclay DW, Higgins C, Thompson R. The partial last squares (PLS) approach to causal modelling, personal computer adoption and use as an illustration. Technol Stud 1995; 2(2): 285-309.

55. Bagozzi RP, Yi Y, Phillips LW. Assessing construct validity in organizational research. Adm Sci Q 1991; 36(3): 421-58.

56. Fornell C, Larcker DF. Structural equation models with unobservable variables and measurement error: Algebra and statistics. J Mark Res 1981; 18(3): 382-8.

57. Wetzels M, Odekerken-Schroder G, van Oppen C. Using PLS path modeling for assessing hierarchical construct models: Guidelines and empirical illustration. MIS Quarterly 2009; 33(1): 177-95.

58. Holguin-Veras J, Jaller M, Van Wassenhove LN, Perez N, Wachtendorf $\mathrm{T}$. On the unique features of post-disaster humanitarian logistics. Journal of Operations Management 2012; 30(7): 494-506.

59. Cooper M, Lambert D, Pagh J. Supply chain management: More than a new name for logistics. Int J Logist Manag 1997; 8(1): 1-14.

60. Dubey R, Ali SS, Aital P, Venkatesh VG. Mechanics of humanitarian supply chain agility and resilience and its empirical validation. International Journal of Services and Operations Management 2014; 17(4): 367-84.

61. Maiers C, Reynolds M, Haselkorn M. Challenges to effective information and communication systems in humanitarian relief organizations. Proceedings of the IEEE International Professional Communication Conference: (IPCC); 2005 July 10-13; Limerick, Ireland.

62. McEntire DA. Coordinating multi-organisational responses to disaster: Lessons from the March 28, 2000, Fort Worth tornado. Disaster Prev Manag 2002; 11(5): 369-79.

63. Moshtari M, Gonealves P. Understanding the drivers and barriers of coordination among humanitarian organizations. Proceedings of the POMS $23^{\text {rd }}$ Annual Conference 2011; 2012 Apr. 27-30; Chicago, IL.

64. Sheffi Y, Rice JB. A supply chain view of the resilient enterprise. MIT Sloan Manag Rev 2005; 47(1): 40-9. 